\title{
Understanding AI governance in Confucian contexts
}

\author{
Ho Manh Tung \\ Ritsumeikan Asia Pacific University \\ Oita, Japan
}

September $2^{\text {nd }}, 2020$

Confucianism has a history of thousands of years in shaping socio-culture in East Asia ${ }^{1,2}$. Hence, even in the digital realm and artificial intelligence (AI), one should not underestimate the influences of Confucian thoughts, given that China has a high publication output in this subject. Recently, China has started the Social Credit System, which is heavily criticized in Western media as a violation of the human right for privacy. ${ }^{3}$

Yet, credible studies done by Westerners in China have shown the Social Credit System is not perceived negatively by the average Chinese people. ${ }^{4}$ This suggests there are cultural nuances and specificities that must be attended to understand.

In order to fully understand how Confucianism shapes the discourses of AI ethics and AI governance in Confucian societies, it seems to me there should be at least three levels of analysis here:

- The individual level: How Confucian concepts of moral development and moral cultivation inform the discourses. For example, how do the foundational values in Confucianism, such as the Five Cardinal Virtues, influence the design and 
ethics of AI? Or what kind of moral tradeoffs do people in the Confucian context are willing to make to reap benefits from AI?

- The societal level: How Confucian concepts of legitimacy, social harmony, and social order inform the discourses. For example, how do the values of the Three Moral Bonds (ruler-ruled, parents-children, husband-wife) influence the design and ethics of AI? What kind of political communication takes place when the government promotes AI usages?

- The external influences: How do international pressure affects the AI governance discourses in these Confucian societies?

It seems to me that the literature has a strong focus on the Chinese government, but the use and governance of $\mathrm{AI}$ in the private sector should also be a major concern for researchers. For example, how do Chinese companies think about the use of AI in surveilling employee's engagement and performance or screening job applicants? Similarly, how do Chinese schools think about the use of AI in surveilling students' engagement?

Williamson (2017) shows that there has been a strong movement toward the datafication of students' emotional lives to govern and change their behaviors toward a more positive feeling. ${ }^{5}$ He coins the term "psycho-informatic power" and argues that this is a new source of authority and control in education. I think, in the context of a Confucian society, which foregrounds the obedience of students, this form of power can manifest stronger. ${ }^{6}$ 
In sum, it is clear that AI governance in Confucian contexts is an underresearched area, especially when it comes to the private sector. Given the growing economic and military power of China, and how AI has been considered as the "trump card strategy" by the Chinese government, researchers have little choice but to understand the cultural nuances that influence AI governance discourses.

\section{References}

1. Vuong, Q. H., Ho, M. T., Nguyen, H. K. T., Vuong, T. T., Tran, T., Hoang, K. L., ... \& La, V. P. (2020). On how religions could accidentally incite lies and violence: Folktales as a cultural transmitter. Palgrave Communications, 6(1), 82.

2. Vuong, Q. H., Bui, Q. K., La, V. P., Vuong, T. T., Nguyen, V. H. T., Ho, M. T., ... \& Ho, M. T. (2018). Cultural additivity: Behavioural insights from the interaction of Confucianism, Buddhism, and Taoism in folktales. Palgrave Communications, 4(1), 143.

3. Roberts, H., Cowls, J., Morley, J., Taddeo, M., Wang, V., \& Floridi, L. (2020). The Chinese approach to artificial intelligence: an analysis of policy, ethics, and regulation. AI \& Society, 1-19. (Article in press) Retrieved from: https:/ / doi.org/10.1007/s00146-020-00992-2

4. Kirk, H. R., Lee, K., \& Micallef, C. (2020). The Nuances of Confucianism in Technology Policy: an Inquiry into the Interaction Between Cultural and Political Systems in Chinese Digital Ethics. International Journal of Politics, Culture, and Society, 1-24. Retrieved from: https://doi.org/10.1007/s10767-020-09370-8 
5. Williamson, B. (2017). Moulding student emotions through computational psychology: Affective learning technologies and algorithmic governance. Educational Media International, 54(4), 267-288.

6. Vuong, Q. H., \& Napier, N. K. (2015). Acculturation and global mindsponge: an emerging market perspective. International Journal of Intercultural Relations, 49, 354-367. 